\title{
Heyde's Syndrome: Case Report and Literature Review
}

\author{
Fernando Côrtes Remisio Figuinha, Guilherme Sobreira Spina, Flávio Tarasoutchi \\ Instituto do Coração - HC-FMUSP, São Paulo, SP - Brazil
}

This study reports the case of Heyde's syndrome and discusses the pathophysiology bases and potential therapies for this syndrome.

\section{Introduction}

The association between aortic stenosis and gastrointestinal bleeding - Heyde's syndrome - has been studied in recent years with major advances in the understanding of its pathophysiological mechanism and therapy. This report presents an illustrative case of Heyde's syndrome and reviews the literature available to date.

\section{Case Report}

Patient A.M., male, 76 years old, sought medical attention complaining of chest tightness, without irradiation, associated with nausea and sweating, usually starting with minor stresses. The patient also presented dyspnea on minimal exertion, orthopnea, paroxysmal nocturnal dyspnea and edema of lower limbs. The patient denied fever. Patient reported episodes of lower gastrointestinal bleeding (LGIB) in small amounts, for six months. He denied other sites of bleeding.

He reported a history of hypertension, type 2 diabetes mellitus, chronic renal failure (CRF) not undergoing dialysis and reported valve problem and exertion fatigue.

On physical examination, he was pale, eupneic. Pulse of $82 \mathrm{bpm}$, respiratory rate of $20 \mathrm{bpm}$, blood pressure 140 x $70 \mathrm{mmHg}$. Cardiovascular examination revealed ejective systolic murmur at aortic focus $+++/ 6+$, irradiating to the suprasternal notch. Pulmonary examination with crackling rales at the bases. Peripheral edema $++/ 4+$, and good peripheral perfusion.

General tests revealed hemoglobin of $6.8 \mathrm{~g} / \mathrm{dl}$, hematocrit $23 \%$, creatinine $1.39 \mathrm{mg} / \mathrm{dL}$. The other tests are shown in Table 1. Initially, the picture of anemia was attributed to the

\section{Keywords}

Aortic valve stenosis; hemorrhage; gastrointestinal hemorrhage; angiodysplasia; Heyde sindrome.

\section{Mailing address: Fernando Côrtes Remisio Figuinha}

Rua Teodoro Sampaio, 408 / 24 - Pinheiros - 05406-000 - São Paulo, SP - Brazil E-mail: fefigas@yahoo.com.br, drfernandofiguinha@gmail.com

Manuscript received September 10 $0^{\text {th }}, 2010$; revised manuscript received March $4^{\text {th }}, 2010$; accepted March $24^{\text {th }}, 2010$.
IRC. However, there was improvement in renal function after volume infusion, characterizing renal dysfunction as acute. Because of heart failure and anemia, a blood transfusion was made.

Iron status revealed anemia likely to be due to iron deficiency (Table 1). Electrocardiogram shown in Figure 1.

Transthoracic echocardiography confirmed important aortic stenosis, valve area $0.5 \mathrm{~cm}^{2}$ and a maximum gradient of 85 $\mathrm{mmHg}$ and average gradient of $52 \mathrm{mmHg}$. Ejection fraction $62 \%$. Left ventricle with diastolic diameter of $56 \mathrm{~mm}$ and stroke diameter of $37 \mathrm{~mm}$.

Coronary angiography revealed $60 \%$ lesion in $1 / 3$ proximal anterior descending artery with no further critical lesions except for some irregularities. LV-Ao gradient of $45 \mathrm{mmHg}$.

Colonoscopy was performed to investigate the LGIB. It revealed angiodysplasia in proximal ascending colon. The presence of gastrointestinal bleeding for angiodysplasia and aortic stenosis suggested the diagnosis of Heyde's syndrome.

The patient's hemoglobin levels remained stable after transfusion performed on admission. After catheterization and with improved cardiac failure symptoms, the patient was discharged and referred to outpatient clinic reassessment for scheduling of surgery for valve replacement.

Two months after discharge, the patient sought the emergency room and was admitted in ICU for decompensated heart failure. Surgery was recommended for aortic valve replacement, but the patient presented clinical worsening because of pulmonary infection, progressing to death from septic shock.

\section{Discussion}

Heyde's syndrome is the association of gastrointestinal bleeding due to angiodysplasia and aortic stenosis (AoS). It was originally described in $1958^{1}$ by Heyde, and in 1992 Olearchyk ${ }^{2}$ defined the combination of aortic stenosis and recurrent bleeding due to gastrointestinal angiodysplasia as Heyde's syndrome.

Vincentelli et $\mathrm{al}^{3}$ showed that $21 \%$ of patients with severe aortic stenosis had skin or mucous bleeding in the six months preceding valve surgery.

Several articles have been published in recent years discussing the pathophysiology little known until the end of the last century, and the treatment of this syndrome. It is related to von Willebrand's type $2 \mathrm{~A}$ acquired syndrome occuring in these patients - hemorrhagic syndrome that arises due to loss of high molecular weight vWF multimers (HMWM) ${ }^{3}$. 
Table 1 - Serum test results

\begin{tabular}{|c|c|c|c|c|c|c|c|}
\hline Variable & 15/Sept & 10/10 (Admission) & after 12 hours & $11 / 0 \mathrm{ct}$ & $12 / 0 \mathrm{ct}$ & $17 / 0 \mathrm{ct}$ & $28 / \mathrm{Nov}$ \\
\hline Hemoglobin (g/dL) & 8,4 & 6,8 & 6,6 & 9,3 & 8,7 & 9,3 & 9,9 \\
\hline Hematocrit (\%) & 27 & 23 & 22 & 29 & 28 & 30 & 32 \\
\hline Mean Corpuscular Volume $\left(\mu \mathrm{m}^{3}\right)$ & 90 & 85 & 85 & 83 & 85 & 83 & 89 \\
\hline $\mathrm{MCH}(\mathrm{pg})$ & 28 & & & & & & 28 \\
\hline RDW (\%) & 14,9 & & & & & & 20,8 \\
\hline Reticulocytes (\%) & & & & & & 2,5 & \\
\hline Leukocytes (per mm³) & 6700 & 4800 & 4300 & 3700 & 4000 & 5000 & 5500 \\
\hline \multicolumn{8}{|l|}{ Differential (\%) } \\
\hline Neutrophils & 77 & 71 & 67 & 68 & 67 & 73 & 72 \\
\hline Lymphocytes & 11 & 13 & 16 & 13 & 12 & 13 & 11 \\
\hline Monocytes & 11 & 12 & 13 & 14 & 16 & 8 & 9 \\
\hline Eosinophils & 1 & 4 & 3 & 4 & 4 & 5 & 7 \\
\hline Basophils & 0 & 0 & 1 & 1 & 1 & 1 & 1 \\
\hline Platelets (per mm³) & 213000 & 172000 & 171000 & 173000 & 164000 & & 159000 \\
\hline CKMB mass (ng/mL) & 2,91 & 4,31 & 3,77 & & & & \\
\hline Troponin (ng/mL) & $<0,2$ & $<0,2$ & $<0,2$ & & & & \\
\hline \multicolumn{8}{|l|}{ Coagulation } \\
\hline Prothrombin time (INR) & 1,01 & 0,99 & & 1 & 1,02 & & 0,9 \\
\hline Thromboplastin time $(\mathrm{R})$ & 1,49 & 1,41 & & 1,3 & 1,27 & & 1,21 \\
\hline Creatinine (mg/dL) & 1,42 & 1,39 & 1,33 & 1 & 1,09 & 0,92 & 1,29 \\
\hline Urea (mg/dL) & 123 & 139 & 128 & 86 & 71 & 35 & 91 \\
\hline Sodium (mEq/L) & 139 & 139 & & 140 & 142 & 139 & 141 \\
\hline Potassium (mEq/L) & 5,6 & 5,3 & & 4,9 & 4,3 & 3,8 & 5,2 \\
\hline Iron $(\mu \mathrm{g} / \mathrm{dL})$ & 22 & & & & & & \\
\hline Ferritin (ng/mL) & 142 & & & & & & \\
\hline Iron Binding Capacity ( $\mu \mathrm{g} / \mathrm{dl})$ & 368 & & & & & & \\
\hline Iron Saturation (\%) & 6 & & & & & & \\
\hline Folic acid (ng/mL) & $>24$ & & & & & & \\
\hline Vitamin B12 (pg/mL) & 2300 & & & & & & \\
\hline
\end{tabular}

The pathophysiological explanation is that with the passage of vWF through the stenotic valve, occurs proteolysis of these multimers by enzyme ADAMTS13 (A disintegrin And Metalloproteinase with Thrombospondin type 1 moitf, member 13) - a protease that acts preferentially under conditions of high shear stress. These HMWM are very important for a proper haemostasis mediated by platelets ${ }^{3}$, binding to platelet glycoprotein Ib. The von Willebrand factor is secreted by endothelial cells into the blood, where it contributes to the formation of platelet thrombi and acts as a mediator of platelet adhesion at the vascular injury site. The first description of the loss of HMWM in Heyde's syndrome was made by Warkentin et $\mathrm{al}^{4}$ in 1992.

The relationship between AoS and platelet function was examined recently ${ }^{3}$. Almost all patients with severe aortic stenosis had decreased percent HMWM and platelet dysfunction. From the first day after surgery for valve replacement, all patients had their HMWM levels and platelet function brought to normal conditions, which proves the relationship between valve disease and hematological abnormality.

As for the high prevalence of angiodysplasia in these patients, it was proposed that hemodynamically significant aortic stenosis may be associated with decreased gastrointestinal perfusion, thereby leading to dilation of blood vessels induced by hypoxia, speeding up the development of fixed vasodilatation, genesis of angiodysplasia.

As for treatment, the doubt that arises when dealing with a patient who has a significant aortic stenosis and gastrointestinal bleeding associated is the conduct that must be taken: should we operate the heart first, with aortic valve replacement, or the intestine, with resection of the bleeding segment? 


\section{Case Report}

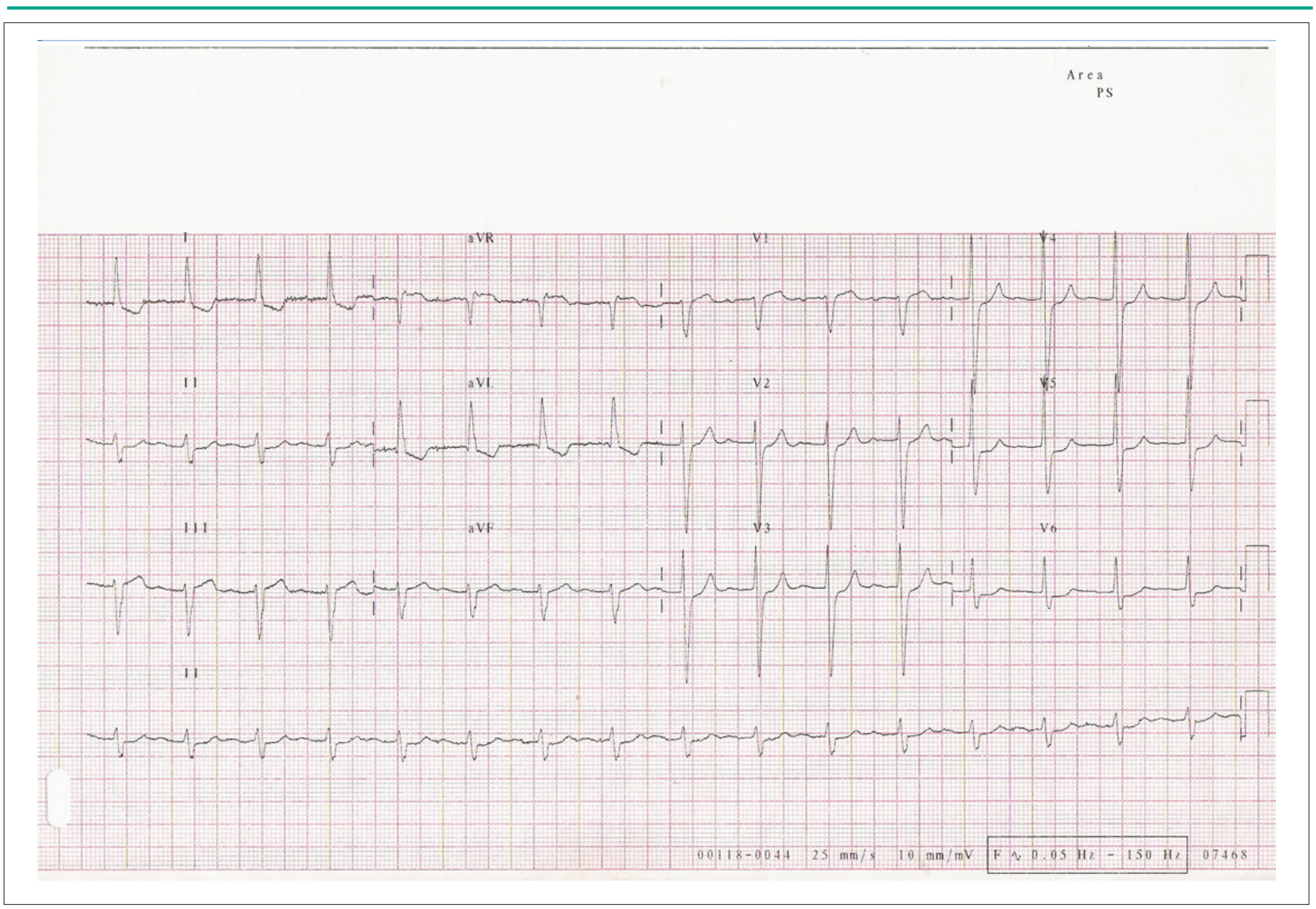

Figure 1 - Resting electrocardiogram showing sinus rhythm, atrioventricular block of $1^{\text {st }}$ degree and left ventricular hypertrophy.

We fear that after the new valve surgery further bleeding may occur. On the other hand, intestinal surgery with AoS is associated with high risk of perioperative cardiovascular complications for valve disease ${ }^{5}$.

Valve surgery alone may lead to regression of the abnormalities that occur in Heyde's syndrome. Recurrence of bleeding only occurs when the pathophysiological mechanism is re-established, either by re-aortic stenosis, either by patient-prosthesis mismatch (defined by effective valve area by body surface $<0.85 \mathrm{~cm}^{2} / \mathrm{m}^{2}$ on echocardiogram $)^{6}$ — where there are still high postoperative aortic gradients even with normofunctioning valves.

The type of valve prosthesis is the biological one, since it does not require anticoagulation after surgery.

When valve surgery cannot be performed, for high surgical risk, some authors ${ }^{7}$ suggest to perform colectomy after identification of the bleeding site as an initial treatment option, knowing that recurrence of bleeding could occur at another site. Today, percutaneous prosthesis ${ }^{8}$ can be performed.

Some authors also suggest octreotide 20 mg once a month ${ }^{7}$ as an alternative treatment to those whose surgery was not successful in resolving the bleeding.

The supplementation of von Willebrand factor seems to be effective to prevent major bleeding complications in the perioperative period ${ }^{9}$, but the long-term treatment of acquired type $2 \mathrm{~A}$ von Willebrand syndrome for valve lesion does not respond well to desmopressin and repeated transfusions of clotting factors, and thus requires surgical correction of aortic stenosis for final resolution of the hematological abnormality.

Thus, the recommended treatment of choice for Heyde's syndrome is aortic valve replacement surgery, which should be performed whenever possible to those who have a history of bleeding and severe aortic stenosis.

\section{Potential Conflict of Interest}

No potential conflict of interest relevant to this article was reported.

\section{Sources of Funding}

There were no external funding sources for this study.

\section{Study Association}

This study is not associated with any post-graduation program. 


\section{References}

1. Heyde EC. Gastrointestinal bleeding in aortic stenosis. N Engl J Med. 1958; 259: 196.

2. Olearchyk AS. Heyde's syndrome. J Thorac Cardiovasc Surg. 1992; 103 (4): 823-4.

3. Vincentelli A, Susen S, Le Tourneau T, Six I, Fabre O, Juthier F, et al. Acquired von Willebrand syndrome in aortic stenosis. N Engl J Med. 2003; 349 (4): 343-9.

4. Warkentin TE, Moore JC, Morgan DG. Aortic stenosis and bleeding gastrointestinal angiodysplasia: is acquired von Willebrand syndrome the lynk? Lancet. 1992; 240 (8810): 35-7.

5. Christ M, Sharkova Y, Geldner G, Maisch B. Preoperative and perioperative care for patients with suspected or established aortic stenosis facing noncardiac surgery. Chest. 2005; 128 (4): 2944-53.
6. Goldsmith IR, Blann AD, Patel RL, Lip GY. Effect of aortic valve replacement on plasma soluble P-selectine, von Willebrand factor and fibrinogen. Am J Cardiol. 2001; 87 (1): 107-10.

7. De Palma GD, Slavatori F, Masone S, Simeoli I, Rega M, Celiento M, et al Acute gastrointestinal bleeding following aortic valve replacement in a patient with Heyde's syndrome. Case report. Minerva Gastroenterol Dietol. 2007; 53 (3): 291-3.

8. Webb JG, Pasupati S, Humphries K, Thompson C, Altweg L, Moss R, et al Percutaneous transarterial valve replacement in selected high-risk patients with aortic stenosis. Circulation. 2007; 116 (7): 755-63.

9. Morishima A, Marui A, Shimamoto T, Sagi Y, Tambara K, Nishima T, et al Successful aortic valve replacement for Heyde syndrome with confirmed hematologic recovery. Ann Thorac Surg. 2007; 83 (1): 287-8. 